\title{
Gender Disparity of Hepatocellular Carcinoma and Metastatic Adenocarcinoma; A Survey Report
}

Samira Haque, Shahila Jalil, Sarah Riaz

Department of Histopathology, Shaikh Zayed Hospital, Lahore

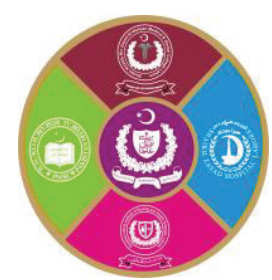

\begin{abstract}
Introduction: Gender discrepancies in context of Hepatocellular carcinoma and Metastatic Adenocarcinoma have widened in recent years. Primary liver cancer is the fifth commonest cancer in men and seventh commonest cancer in women. Metastatic adenocarcinoma of liver shows a poor prognosis as compared to Hepatocellular Carcinoma. It is associated with an average survival of 5-6 months. Aims \& Objectives: To observe the incidence of Hepatocellular Carcinoma and Metastatic Adenocarcinoma in different age groups of men and women in Pakistan. Place and duration of study: This study was carried out at the Gastroenterology and Histopathology Departments of Shaikh Zayed Teaching Hospital, Lahore from November 2010 till January 2014. Material \& Methods: 101 patients were enrolled in the study. Their demographics like age and gender were noted. Hepatocellular carcinoma and metastatic Adenocarcinoma was confirmed with ultrasonography and histopathological reports. Patients were grouped as per diagnosis of Hepatocellular carcinoma (HCC); Group A or metastatic Adenocarcinoma; Group B. Results: It was observed that in Group A, frequency/percentage of Hepatocellular carcinoma in males was 58/78.3\% and in female was 16/21.6\%. Mean age of males was 49.48 years with age range 20-80 years. Mean age of females was 58.40 years with age range 33-75 years. A significant difference was observed $(\mathrm{P}<0.05)$ when mean age of males was compared with age of females. Whereas in Group B, Frequency and mean age of metastatic Adenocarcinoma was found to be $17 / 62.9 \%$ in males and $10 / 37 \%$ in females, while Mean age of male and female was found to be 51.53 years with age range 33-66 years and 50.1 years with age range 30-66 years respectively. Conclusion: In our local setting HCC is more common in middle age men compared to females. In females it is more prevalent in their menopausal age. On the other hand metastatic Adenocarcinoma from GI is common in both middle aged males and females however men are at a higher risk to develop metastasis than females
\end{abstract}

Key words: Gender, hepatocellular carcinoma, metastatic Adenocarcinoma.

\section{INTRODUCTION}

$\mathrm{H}$ epatocellular carcinoma (HCC) is the commonest of all primary liver cancers constituting about $85 \%$ to $90 \%$ of these tumors. The highest number $(85 \%)$ is seen in developing countries especially Asia ${ }^{1,2}$. It carries a poor prognosis as only $10-20 \%$ cases of Hepatocellular carcinomas can be removed surgically. In the remaining cases the disease is fatal within 3 to 6 months ${ }^{3}$.

HCC incidence and mortality rates have persistently increased, especially among middle-aged black with age range 50-59 years. It is the fifth most prevalent cancer in men and seventh most prevalent cancer in women. HCC shows a male predominance with male: female ratio between $2: 1$ and 4:1. General behavior of Hepatocellular carcinoma was more aggressive in males but the average survival time was similar in both genders ${ }^{4}$. Hepatocellular carcinoma is rarely seen under 40 years of age and peaks at 70 years. Men were younger in age than women at time of diagnosis ${ }^{2}$.

Infection with Hepatitis $\mathrm{B}$ and $\mathrm{C}$ virus, alcoholic liver disease, and non-alcoholic fatty liver due to the metabolic syndrome are the principal risk factors for HCC. Most of these risk factors are associated with cirrhosis. It was observed that 80 to $90 \%$ of patients with Hepatocellular carcinoma had underlying cirrhosis. The endemic areas of Asia and Africa show $90 \%$ infection rate which is attributed to vertical transmission of $\mathrm{HBV}$ from mother to newborn because of incorporation of HBV into host DNA $^{3,5,6,7}$. However the known cause of Hepatocellular carcinoma is cellular mutation which makes the cells divide at a faster rate and also causes the cells to avoid apoptosis ${ }^{8}$.

About $70-90 \%$, Hepatocellular carcinomas develop in patients with chronic liver disease due to $\mathrm{HCV}$ through the stage of cirrhosis, which is more 
frequent in women than in men $^{3}$. It is proposed that repeated attempts by the immune system of body to clear the virus from the hepatocytes may cause errors during repair and lead to carcinogenesis ${ }^{8}$.

Experimental studies have revealed that men show a higher incidence of hepatocellular carcinoma as compared to women. This may be due to the stimulatory effects of androgens and the protective effects of estrogen. It is proposed that active androgen receptor pathway increases the risk of HCC. To support this theory an interaction was found between the $\mathrm{X}$ protein of hepatitis B virus and the androgen pathway ${ }^{9}$. It is suggested that hormone progesterone may play a role in its pathogenesis since it is a precursor of both androgens and estrogens ${ }^{10}$.

High-grade tumors carry a poor prognosis, while low-grade tumors may remain symptom free for many years ${ }^{11}$. The macroscopic growth pattern of HCC is subdivided into nodular, massive and infiltrative. The constituent cells of a well differentiated HCC resemble hepatocytes. They occur in trabeculae, cords and nests. The cells of a poorly differentiated HCC are incohesive, pleomorphic, anaplastic and may also form giant cells ${ }^{12}$.

Metastatic lesions were more common as compared to HCC. However the ratio of metastatic Adenocarcinoma and primary HCC was almost equal ${ }^{13}$. Because of its rich and dual blood supply, liver is a common site for metastasis. Metastatic tumors in the liver are 20 times more frequent than primary tumors and carry a poor prognosis, with a median survival of 5 months ${ }^{14}$. In half of these cases the primary tumor was in the gastrointestinal tract. These are usually found at a stage when remedial surgical resection is impossible; these tumors have incidence rates that approach mortality rates ${ }^{15}$.

Various parameters have been noted for prognostic value in patients with HCC. These include patient demographics like age and gender with frequency of HCC and metastatic Adenocarcinoma. Present study was conducted to determine these demographics in our population.

\section{MATERIAL AND METHODS}

This study was conducted on 101 patients. Patients of all ages and both sexes were included. Patients were taken from outpatient department of Gasteroentrology of Shaikh Zayed Teaching Hospital Lahore. Hepatocellular carcinoma and metastatic Adenocarcinoma was confirmed with ultrasonography and histopathological reports.Histopathology of liver tissue samples was carried out by
Histopathology Department of Shaikh Zayed Teaching Hospital Lahore. Duration of study was from 2010 to 2014. Patients were classified as group A (diagnosed with HCC) and group B (diagnosed with metastatic Adenocarcinoma). Group A comprised of 58 males and 16 females. Group B comprised of 17 males and 10 females. To examine the effect of gender on liver tumors, both groups underwent surgical resection of the tumor. Patients with any other hepatocellular disease were excluded from the study. Demographics like age, gender and frequency of both male and female patients were noted. Letter of consent was taken from patients. Study was approved by Ethical Committee of Shaikh Zayed Teaching Hospital Lahore.

\section{Statistical analysis:}

Data was entered in computer program SPSS 18. Variables were given in percentages, frequencies and as Pie charts.

\section{RESULTS}

Frequency and mean age of Hepatocellular carcinoma in males and females was tabulated in Table-1. It was observed that frequency/percentages of HCC in males was 58/78.3\% and in females was $16 / 21.6 \%$. Mean age of males was 49.48 years with age range 20-80 years. Mean age of females was 58.40 years with age range $33-75$ years. A significant difference was observed $(\mathrm{P}<0.05)$ when mean age of male was compared with age of females.

Frequency and mean age of metastatic Adenocarcinoma in males and females was tabulated in Table-2. It was observed that frequency/ percentages of metastatic Adenocarcinoma in males was $17 / 62.9 \%$ and in females was $10 / 37 \%$. Mean age of males was 51.53 years with age range 33-66 years. Mean age of females was 50.1 years with age range 30-66 years.

\begin{tabular}{|l|l|l|l|}
\hline Gender & $\begin{array}{l}\text { Frequency \& } \\
\text { percentages }\end{array}$ & $\begin{array}{l}\text { Age range } \\
\text { (yrs) }\end{array}$ & $\begin{array}{l}\text { Mean age } \\
\text { (yrs) }\end{array}$ \\
\hline Male & $58(78.3 \%)$ & $20-80$ & $49.48 \pm 11.51$ \\
\hline Female & $16(21.6 \%)$ & $33-75$ & $58.40 \pm 7.16^{*}$ \\
\hline
\end{tabular}

$* \mathrm{P}<0.05=$ Significant difference.

Table-1: Frequency and mean age of Hepatocellular carcinoma in males and females

\begin{tabular}{|l|l|l|l|}
\hline Gender & $\begin{array}{l}\text { Frequency \& } \\
\text { percentages }\end{array}$ & $\begin{array}{l}\text { Age range } \\
\text { (years) }\end{array}$ & $\begin{array}{l}\text { Mean age } \\
\text { (years) }\end{array}$ \\
\hline Male & $17(62.9 \%)$ & $33-66$ & $51.53 \pm 8.88$ \\
\hline Female & $10(37.0 \%)$ & $30-66$ & $50.10 \pm 13.03$ \\
\hline
\end{tabular}

Table-2: Frequency and mean age of metastatic Adenocarcinoma in males and females 


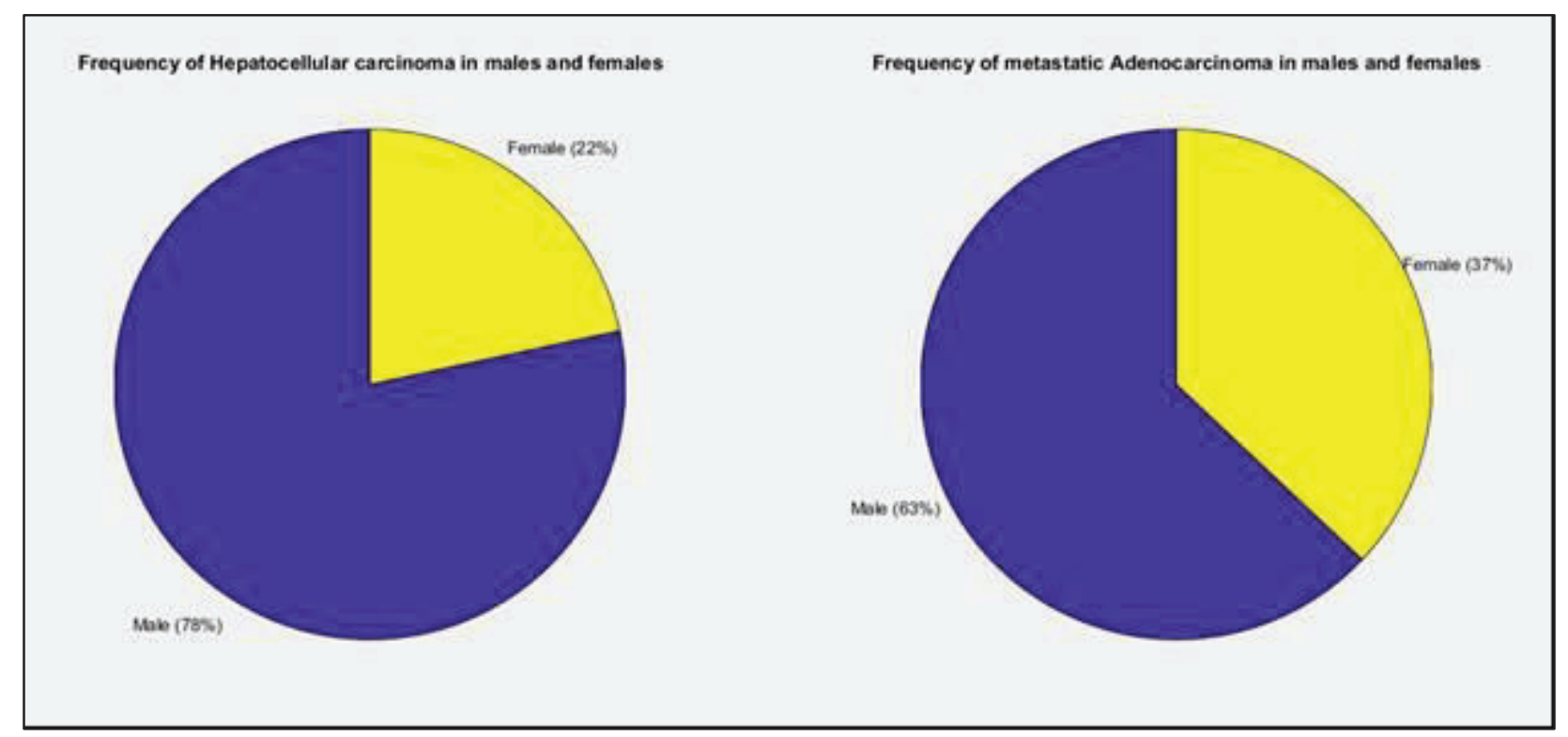

\section{DISCUSSION}

Hepatocellular carcinoma accounts for $90 \%$ of all liver cancers. Based on clinical information, HCC appears to develop earlier in men than in women, and predominately it is a disease of men and postmenopausal women ${ }^{16,17}$.

Present study observed that frequency/percentages of Hepatocellular carcinoma was significantly higher in males than females. Our study is in line with studies which reported that men were affected with HCC two to four times more often than women $^{18}$, This is partly due to higher frequency of viral hepatitis and alcoholic cirrhosis in $\operatorname{men}^{19}$. Additional experimental studies have revealed that higher incidence of $\mathrm{HCC}$ in men as compared to women might be due to the stimulatory effects of androgen in males and the protection afforded by estrogen in females. ${ }^{9,20}$.

In Pakistan Genotype 3 was the predominant type in all the provinces. In Punjab the most common Genotype was G1 which is the second most common genotype in Pakistan. In addition few untypable genotypes were noticed in Sindh, Khyber Pakhtunkhwa and Balochistan provinces. ${ }^{21}$

Alcohol related morbidity was $0.5 \%$ in males, $0.1 \%$ in females and $0.3 \%$ in both sexes. Age Standardized Death Rates (ASDR) was 37.4 in males and 33 in females. ${ }^{22}$

According to our study the mean age of male was 49.48 years. Mean age of female was 58.40 years. A statistical analysis also observed that women are $24 \%$ more at risk of developing $\mathrm{HCC}$ in their menopausal age due to decrease female sex hormone $^{19}$. Experimentally it is proved that oophorectomy performed during premenopausal years increased the risk of $\mathrm{HCC}^{23}$, suggesting that female sex hormones progesterone or estrogen may be protective against $\mathrm{HCC}^{9}$. Another study found that number of menopausal women with cirrhosis may lead to $\mathrm{HCC}^{24}$.

However, a study reported that HCC usually occurs 20-30 years after the initial liver insult ${ }^{17}$. In general it is reported that risk of developing Hepatocellular carcinoma in patients who are infected with hepatitis B virus increases with older age at the time of infection, male gender and co-infection with the human immunodeficiency virus or HIV etc ${ }^{25}$.

Frequency and mean age of metastatic Adenocarcinoma in males and females showed that frequency/percentages of males was $17 / 62.9 \%$ and of females was $10 / 37 \%$. Mean age of males was 51.53 years with age range 33-66 years. Mean age of females was 50.1 years with age range 30-66 years. According to a study women with age 55 years and more had significantly worse survival than older men ${ }^{4}$. Our study is in line with a study which demonstrates, that menstrual factors such as age of menopause and years of fertility are associated with metastatis ${ }^{26}$. However, a study reported that age range of metastatic Adenocarcinoma is between 18-44 years and young patients with metastatic Adenocarcinoma have a more aggressive disease than other ages ${ }^{27,28}$.

Present study found that liver was the dominant metastatic site for gastrointestinal tract (GI) tumors in $80 \%$ cases. However, a study reported that liver was the metastatic site for GI tumors in $38 \%$ of patients $^{29}$. Our study is in line with studies which reported that as compared to women, men are twice as likely to develop metastatic Adenocarcinoma of liver from GI. According to studies the dominant 
pattern of GI primary tumors metastasizing to the liver is due to venous drainage of GI directly to the liver ${ }^{30,31,32}$.

Present study found that gall bladder was the metastatic site for $20 \%$ cases with age range $30-66$ years. However, a study found that the incidence of gallbladder cancer steadily decreased in patients older than 50 years, but increased in younger patients $^{33}$. Another study found a considerable female predominance worldwide, with female-tomale ratios of approximately $2.5: 1$ to $3: 1^{34}$. It is reported that gall bladder cancer (GBC) is characterized by local invasion, extensive regional lymph node metastasis, vascular encasement, and distant metastases. Patients with metastatic GBC have a poor prognosis ${ }^{35,36}$.

\section{CONCLUSION}

It is therefore concluded that $\mathrm{HCC}$ is more common in middle age men compared to females. In females it is more prevalent in their menopausal age due to the deficiency of female sex hormones as the studies confirmed. On the other hand metastatic carcinoma from GI is common in both middle aged male and female however men are at a higher risk to develop metastasis than females. Screening and early treatment can limit this problem. Further investigations are required.

\section{REFERENCES}

1. Bosch FX, Ribes J, Diaz M, et al; Primary liver cancer: worldwide incidence and trends. Gastroenterology. 2004 Nov; 127(5 Suppl 1):S5-S16.

2. Hashem B. El-Serag, Hepatocellular Carcinoma N Engl J Med 2011; 365:1118-1127

3. Hefaiedh R, Ennaifer R, Romdhane H, Ben Nejma H, Arfa N, Belhadj N, Gharbi L, Khalfallah T. Gender difference in patients with hepatocellular carcinoma. Tunis Med. 2013 Aug-Sep; 91(8-9): 505-8.

4. Kumagi T, Hiasa Y, Hirschfield GM; Hepatocellular carcinoma for the non-specialist. BMJ. 2009 Dec 4; 339: b5039

5. Hendifar A, Yang D, Lenz F, Lurje G, Pohl A, Lenz C, Ning Y, Zhang W, Lenz HJ. Gender disparities in metastatic colorectal cancer survival. Clin Cancer Res. 2009Oct15;15(20):6391-7

6. Njei B, Rotman Y, Ditah I, Lim JK. Emerging trends in hepatocellular carcinoma incidence and mortality. Hepatology. 2014;61:191-199

7. El-Serag HB, Kanwal F. Epidemiology of hepatocellular carcinoma in the United States:
Where are we? Where do we go? Hepatology. 2014; 60:1767-1775

8. Mittal S, El-Serag HB. Epidemiology of hepatocellular carcinoma: consider the population. J Clin Gastroenterol. 2013;47 Suppl:S2-S6.

9. Schütte K, Kipper M, Kahl S, Bornschein J, Götze T, Adolf D, Arend J, Seidensticker R, Lippert H, Ricke J. Clinical characteristics and time trends in etiology of hepatocellular cancer in Germany. Digestion. 2013;87:147-159

10. Chen CJ, Yang HI, Su J, Jen CL, You SL, Lu SL et al. "Risk of Hepatocellular Carcinoma Across a Biological Gradient of Serum Hepatitis B Virus DNA Level".JAMA.2006;295(1):65-73

11. Yeh SH, Chen PJ. Gender disparity of hepatocellular carcinoma: the roles of sex hormones. Oncology.2010Jul;78 Suppl 1:172-9.

12. Ballestri S, Romagnoli D, Nascimbeni F, Francica G, Lonardo A. Role of ultrasound in the diagnosis and treatment of nonalcoholic fatty liver disease and its complications. Expert Rev Gastroenterol Hepatol. 2015 Feb 19:1-25.

13. Reynolds AR, Furlan A, Fetzer DT, Sasatomi E, Borhani AA, Heller MT, Tublin ME.Infiltrative Hepatocellular Carcinoma: What Radiologists Need to Know. Radiographics. 2015 Mar-Apr; 35(2): 371-386.

14. Sattar A, Khan AM, Anjum S, Naqvi A. Role of ultrasound guided fine needle aspiration cytology in diagnosis of space occupying lesions of liver. J Ayub Med Coll Abbottabad. 2014 Jul-Sep; 26(3):334-6.

15. Hawksworth J, Geisinger K, Zagoria R, Kavanagh P, Howerton R, Levine EA, Shen P. Surgical and ablative treatment for metastatic adenocarcinoma to the liver from unknown primary tumor. Am Surg. 2004 Jun;70(6):512-7.

16. Spartlin JL, Chu Q, King K and Mulder K. Targeting metastatic upper gastrointestinal adenocarcinomas. World J Clin Oncol. 2011 Mar 10; 2(3): 135-149.

17. Shimizu I. Impact of oestrogens on the progression of liver disease. Liver International. 2003; 23(1):63-69.

18. Forner A, Llovet JM, Bruix J; Hepatocellular carcinoma.Lancet.2012Mar31;379(9822):1245-55

19. El-Serag HB. Epidemiology of hepatocellular carcinoma. Clinics in Liver Disease. 2001; 5(1): 87-107.

20. Mucci LA, Kuper HE, Tamimi R, Lagiou P, Spanos E, Trichopoulos D. Age at menarche and age at menopause in relation to hepatocellular carcinoma in women. British Journal of Obstetrics and Gynaecology. 2001; 108(3): 291-294 
21. Attaullah S, Khan S and Ali I. Hepatitis C virus genotypes in Pakistan: a systemic review. Virol J. 2011; 8: 433.

22. Who.int. (2018). [online] Available at: http://www.who.int/substance_abuse/publicatio ns/global_alcohol_report/profiles/pak.pdf [Accessed 23 Oct. 2018].

Alcohol per capita $(15+)$ consumption (in litres of pure alcohol). Average ... Prevalence of heavy episodic drinking* (\%), 2010 ... Liver cirrhosis, males / females.

23. El-Serag HB. Hepatocellular carcinoma: an epidemiologic view. Journal of Clinical Gastroenterology.2002;35(5,supplement2):S72-78

24. Yu MW, Chang HC, Chang SC, et al. Role of reproductive factors in hepatocellular carcinoma: impact on hepatitis B- and C-related risk. Hepatology. 2003; 38(6):1393-1400.

25. Codes L, Asselah T, Cazals-Hatem D, et al. Liver fibrosis in women with chronic hepatitis $\mathrm{C}$ : evidence for the negative role of the menopause and steatosis and the potential benefit of hormone replacement therapy. Gut. 2007; 56(3): 390-395.

26. Yang D, Hendifar A, Lenz C, Togawa K, Lenz F, Lurje G et al. Survival of metastatic gastric cancer: Significance of age, sex and race/ ethnicity.J Gastrointest Oncol.2011Jun;2(2):77-84

27. Kirk GD, Mehta SH, Astemborski J, Galai N, Washington J, Higgins Y, Balagopal A, Thomas DL. HIV, age, and the severity of hepatitis C virus-related liver disease: a cohort study. Ann Intern Med. 2013 May 7; 158(9):658-66.

28. Freedman ND, Chow WH, Gao YT, Shu XO, Ji BT, Yang G, et al. Menstrual and reproductive factors and gastric cancer risk in a large prospective study of women.Gut.2007;56:1671-7

29. Wang JY, Hsieh JS, Huang CJ, Huang YS, Huang TJ. Clinicopathologic study of advanced gastric cancer without serosal invasion in young and old patients. J Surg Oncol. 1996; 63: 36-40

30. Lazaridis G, Pentheroudakis G, Fountzilas G, Pavlidis N. 49 patients and systematic review of the literature. Liver metastases from cancer of unknown primary (CUPL): a retrospective analysis of presentation, management and prognosis in 49 patients and systematic review of the literature. Cancer Treat Rev. 2008 Dec; 34(8): 693-700.

31. Yoshimitsu $\mathrm{K}$, Honda $\mathrm{H}$, Kuroiwa $\mathrm{T}$, Irie $\mathrm{H}$, Aibe H, Tajima T, Chijiiwa K, Shimada M,
Masuda K. Liver metastasis from gallbladder carcinoma: anatomic correlation with cholecystic venous drainage demonstrated by helical computed tomography during injection of contrast medium in the cholecystic artery. Cancer. 2001 Jul 15; 92(2): 340-8.

32. Hess KR, Varadhachary GR, Taylor SH, Wei W, Raber MN, Lenzi R, Abbruzzese JL. Metastatic patterns in adenocarcinoma. Cancer. 2006 Apr 1; 106(7): 1624-33.

33. Schottenfeld D and Fraumeni J. Cancer. Epidemiology and Prevention. 3rd. Oxford University Press; 2006: 787-800.

34. Andrew X. Zhu, Theodore S. Hong, Aram F. Hezel David A. Kooby. Current Management of Gallbladder Carcinoma. The Oncologist. 2010; 15(2): 168-181

35. Brenner H, Rothenbacher D, Arndt V. Epidemiology of stomach cancer. Methods Mol Biol. 2009; 472: 467-77

36. Kiran RP, Pokala N, Dudrick SJ. Incidence pattern and survival for gallbladder cancer over three decades--an analysis of 10301 patients. Ann Surg Oncol. 2007 Feb; 14(2): 827-32.

\section{The Authors:}

Dr. Samira Haque

Associate Professor,

Department of Histopathology,

Shaikh Zayed Hospital, Lahore.

Dr. Shahila Jalil

Associate Professor,

Department of Histopathology,

Shaikh Zayed Hospital, Lahore.

Dr. Sarah Riaz

Assistant Professor,

Department of Histopathology,

Shaikh Zayed Hospital, Lahore.

\section{Corresponding Author:}

Dr. Samira Haque

Associate Professor,

Department of Histopathology,

Shaikh Zayed Hospital, Lahore.

E-mail: drsameerahaque@gmail.com 